\title{
Factors Impacting Corn (Zea mays L.) Establishment and the Role of Uniform Establishment on Yield
}

\author{
Lindsey Novak, Joel Ransom \\ Department of Plant Sciences, North Dakota State University, Fargo, ND, USA \\ Email: lindsey.novak@ndus.edu
}

How to cite this paper: Novak, L. and Ransom, J. (2018) Factors Impacting Corn (Zea mays L.) Establishment and the Role of Uniform Establishment on Yield. Agricultural Sciences, 9, 1317-1336. https://doi.org/10.4236/as.2018.910092

Received: October 3, 2018

Accepted: October 28, 2018

Published: October 31, 2018

Copyright $\odot 2018$ by authors and Scientific Research Publishing Inc. This work is licensed under the Creative Commons Attribution International License (CC BY 4.0).

http://creativecommons.org/licenses/by/4.0/

\section{(c) (i) Open Access}

\begin{abstract}
Information from actual farm fields can help corn producers understand the value and importance of establishing uniform crop emergence and within-row plant spacing. Thirty-eight fields planted with corn (Zea mays L.) by North Dakota producers were evaluated to determine the effects of uneven plant emergence timing and within-row plant space variability, as well as identifying contributing factors. Rows within a planter's width with the most variability yielded $6 \%$ less than the least variable rows. Individual ear weights decreased as the number of days after normal emergence (date when $50 \%$ of plant stand emerged) increased. Ears next to within-row gaps $(>30.5 \mathrm{~cm})$ weighed $11 \%$ more than the normally spaced plants. Combined ears from both plants situated $<5.1 \mathrm{~cm}$ apart weighed $36 \%$ more than from a single ear from normally spaced plants. Surface residue and planting speed impacted stand establishment variability more often than other factors measured. Producers should assess each field environment individually in order to identify best practices to achieve uniform stand establishment.
\end{abstract}

\section{Keywords}

Planting Conditions, Uniform Plant Establishment, Corn Yield

\section{Introduction}

There are many farming practices that contribute to maximum yield in corn (Zea mays L.). Planting high yielding hybrids, applying fertilizer and controlling pests are common practices. However, there is one major practice affecting corn yield that many overlook-establishing a uniform plant stand. Uniform plant stand establishment includes plant emergence uniformity and within-row plant 
spacing variability. Previous studies have shown a yield reduction when corn plantings have uneven emergence timing [1] [2] [3] [4]. Within-row plant spacing variability also has an impact on individual plant yield; however, the significance of overall yield reduction can be variable [2] [5] [6]. Stand establishment can be adversely affected by planting in cool, wet soils that are common during the recommended planting period in North Dakota. The presence or onset of cold soil temperatures during imbibition may cause seed injury. More specifically, when a dry seed imbibes cold water, typically $10^{\circ} \mathrm{C}$ or below, injury may occur. This injury results in seed death or abnormal mesocotyl and coleoptile development, injuries that are irreversible [7]. Seeds in soils that reach $12^{\circ} \mathrm{C}$ to $13^{\circ} \mathrm{C}$ may begin to emerge in approximately seven days [8]. However, temperatures that are unevenly distributed through the seed bed will impact variability in germination. Uneven soil temperature around the planted seed can be caused by cool rainfall, soil type, residue cover and seeding depth [8]. Management practices that may affect stand establishment include previous crop, as well as the amount of residue, tillage methods, planter type, planting speed and seeding rate. In order for the seed to imbibe moisture, seed to soil contact is crucial. Factors that may cause uneven seed to soil contact are high residue levels, cloddy seed beds, and air contact from open planter furrows when planting into excessively wet soils [8]. Tillage operations can be the primary cause of uneven soil moisture resulting in uneven plant emergence timing [4]. Other management practices that have been shown to affect stand establishment are planting date, planter type, planting speed and seeding rate [9] [10]. Little research on this topic has been conducted specifically in North Dakota. There is a need for local data on this topic in order to assist producers in understanding the importance of establishing uniform plant emergence, within-row plant spacing and factors that might be managed to improve uniformity.

\section{Objectives}

The objectives of this research were to quantify the variability in plant emergence timing and within-row plant spacing of corn within farmers' fields in North Dakota and measure their effects on yield and to determine the factors that contribute to uneven emergence timing and within-row plant spacing variability. From the data collected and reported, producers will better understand the importance of uniform stand establishment and the best practices to achieve it.

\section{Materials and Methods}

Field observations were made during the 2013 and 2014 growing seasons in a total of thirty-eight fields planted by North Dakota corn producers. North Dakota State University (NDSU) Extension agents and specialists assisted in this project by conducting the survey observations in their counties. The list of counties, region of the state where they are located, and number of fields observed are summarized in Table 1. Figure 1 shows geographical locations of counties. 
Table 1. North Dakota county locations and number of fields sampled in 2013 and 2014.

\begin{tabular}{cccc}
\hline \multirow{2}{*}{ County } & Region $^{\dagger}$ & 2013 & 2014 \\
\cline { 3 - 4 } Benson & NE & Fields sampled & Fields sampled \\
Eddy & NE & 3 & - \\
Foster & NE & 1 & 1 \\
Ramsey & NE & 2 & 1 \\
Steele & NE & 1 & - \\
Walsh & NE & - & 1 \\
Wells & NE & 1 & - \\
Renville & NW & 1 & 1 \\
Ward & NW & 2 & 2 \\
Barnes & SE & 3 & 1 \\
LaMoure & SE & 3 & 2 \\
Stutsman & SE & 3 & - \\
Sargent & SE & 2 & 3 \\
Stark-Billings & SW & - & - \\
Total & & 3 & 13 \\
\hline
\end{tabular}

${ }^{\dagger}$ Northeast (NE), Northwest (NW), Southeast (SE), Southwest (SW).

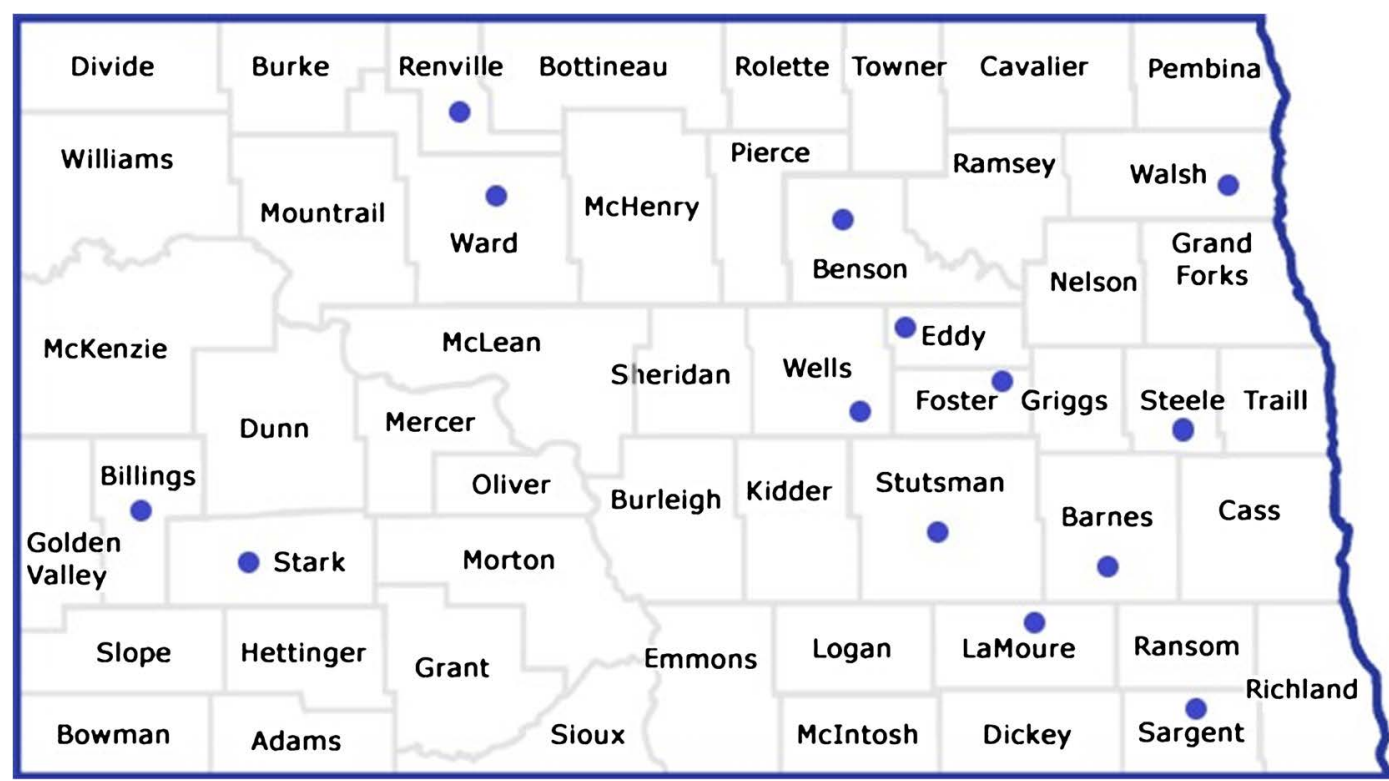

Figure 1. Geographical locations of fields sampled.

Fields within a county were chosen based on accessibility and their general representativeness of corn fields in the area. The final number of fields sampled per county was based on various factors e.g. participant time availability and weather impacts on harvestable fields. The following information was obtained 
from the grower of each field soon after planting: tractor wheel type, corn planter model, planting date, planting rate, hybrid, previous crop, seeding depth, row spacing, planting speed, tillage, tillage time of year and air pressure of tractor tires and seeder. Farmers planted differing hybrids and had varied seed treatments (data not shown).

Within each field site, three randomly selected areas were demarcated for detailed measurement. These three areas were referred to as sample unit one, two and three. A minimum of five observational field visits were made to each field site. The closest North Dakota Agriculture Weather Network (NDAWN) station to the field location was used to obtain data on rainfall, soil temperature, and air temperature. Rainfall amount for the periods between the initial field visits and subsequent visits were calculated from these data, as were average soil and air temperatures were calculated from the previous field visit to that current days field visit. For the purpose of discussing general planting conditions, field locations were categorized by their regional location within the state (NE, NW, SE, $\mathrm{SW}$ ). For each of these regions air temperature and total rainfall were averaged for 1 May through 31 May. Median planting dates for each region were calculated by referring to the planting date recorded for each field. The soil temperature was averaged for each region using the bare soil temperature at $10 \mathrm{~cm}$ below the soils surface for the two weeks after the planting date for that region.

The first field site visit occurred at or near planting. Individual sample units were $9.14 \mathrm{~m}$ long and as wide as the number of planter rows on the planter used to plant the field. For example, a twelve-row planter had a sample unit width of 12 rows. In order to decrease the work load for participating extension agents, fields that were planted with planters over 12 rows (e.g. 36 row), half of the rows were monitored. These rows included the most exterior planted wheel row into the center planted rows. Percent residue was estimated once for each of the sample units by following the steps listed in the United States Department of Agriculture, Soil Conservation Service, Corn and Soybean Crop Residue Management Guide, USDA (1992). The values from each of the sample units were averaged and this average was used to describe the entire field and used in subsequent analysis. Soil moisture was estimated and was categorized as being dry, moist or soggy. Dry soil was defined as soil that did not hold together when trying to form into a ball. Soil that held together when made into a ball was defined as moist, and if water ran out of the formed ball and over the hand, the soil was defined as soggy.

The number of accumulated corn growing degree days (AGDD) needed from time of planting to time of emergence using values based in Fahrenheit scale is approximately 120 AGDD [11]. Therefore, the second field visit occurred at least 120 AGDD after planting but no earlier than VE50. VE50 is defined as the growth stage when $50 \%$ of the plant density has emerged [6]. Corn growing degree days were obtained from nearby NDAWN weather stations as calculated using its Corn Growing Degree Day application. The VE corn growth stage is 
defined as when the coleoptile has emerged from the soil's surface [11]. During this second field visit, the number of plants in VE were counted and recorded for each row in each of the sample units separately. In sample unit one only, at least three VE plants that also had neighboring plants on both sides, were marked with a red flexible plastic stake. The red stake was dated for that day and identified the plant as a normal emerged (NED) plant. Normal emerged plants are defined as a plant that emerged at the time of 120 AGDD or VE50, therefore representing the plants that emerged most uniformly. These NED plants were used for comparison purposes later in the experiment. At this time, the presence of side wall compaction was investigated by digging away soil at the base of plants in at least one spot in each row. Side wall compaction and rooting restrictions were documented when corn roots were growing horizontally along the soil profile. Seed depth was measured and recorded. A soil penetrometer (DICKEY-John, Auburn, IL) was used to quantify penetration resistance in fields located in Sergeant and Stutsman County. At least 10 readings were conducted for each row in all sample units to a depth of $60 \mathrm{~cm}$. The average penetration resistance for each row was recorded.

In 2014, any row planted within a tire track was identified by indicating the type of wheel track associated with that row. Types of wheel tracks included tractor, planter, seed hopper, fertilizer hopper or any combination of the four types. This step was included in order to identify any increased stand establishment variability associated with planting implement arrangements used by producers.

The third field visit was conducted no less than $7 \mathrm{~d}$ from the second field visit date. The total number of plants present in each row was counted and recorded for sample units one two and three. In sample unit one, each plant in the VE stage, that also had neighboring plants on both sides, were marked with an orange colored stake and dated for that day. These plants were identified as late emerged plants. The fourth field visit occurred no less than $7 \mathrm{~d}$ from the third field visit date. The total number of plants present in each row and each sample unit were counted and recorded. In sample unit one, each plant in the VE stage that also had neighboring plants on both sides, were marked with and orange colored stake and dated for that day. These plants were identified as late emerged plants. Doubles and skips were counted in all sample units. In sample unit one only, doubles and plants next to skips were marked with an orange stake. Skips were identified as gaps greater than $30.5 \mathrm{~cm}$ between two plants and doubles were identified as two plants with a planting space less than $5.1 \mathrm{~cm}$.

In 2013, overall stand establishment variability and within-rows was characterized by differences in plant emergence over time. Within a location and replication, the row with the highest change in plant emergence over time (i.e. the row with the largest percentage of plants emerging after the first flush of emergence) was identified as the most variable, the row with the second highest change in plant emergence over time was identified as the second most variable row and so 
on. Within-row plant spacing was measured on the most and least variable rows in sample unit one only, from which standard deviation was calculated utilizing the built in mathematical function formula in Microsoft Excel.

After the review of 2013 data changes to the method in characterization of variability within the rows were made in 2014. The literature contains multiple studies concluding that not only uneven plant emergence timing affects yield, but also within row plant spacing variability. Therefore, it was felt that the amount of skips and doubles within-the-row should also be accounted for, as well as the total number of plants in the row, when accessing overall variability in stand establishment and within-row variability. These changes were made to the identification process and were applied in 2014. Relative overall variability (V) within-rows was accessed in 2014 by applying all plant establishment outcome factors into a calculation. These factors included the following for each individual row: final stand count (b1), first stand count (b2), total skips (b3), total doubles (b4), largest number of plants in a row from all rows in the sample unit (b5). Each factor was weighted equally based on the total number of plants in that row and were summed together as described in the following equation (Equation (1)):

$$
\mathrm{V}=\{[\mathrm{b} 1-\mathrm{b} 2] /[\mathrm{b} 1]\}+[\mathrm{b} 3 / \mathrm{b} 1]+[\mathrm{b} 4 / \mathrm{b} 1]+[\mathrm{b} 1 / \mathrm{b} 5]
$$

Equation (1) was applied to each row. The row with the highest value from the calculation was identified as the most variable row for that plot. The row with the second highest value was identified as the second most variable row and so on until the second least and least variable row were also identified. Within-row plant spacing was measured and recorded on the most and least variable rows in sample unit one only.

Harvest took place on the fifth field visit. Harvest occurred any time after the kernels showed black layer and before the producer harvested the field. In all sample units the most, second most, second least and least variable rows were hand harvested in the $9.14 \mathrm{~m}$ length of row. The ears (grain and cob) were weighed using an UltraSport V2-30 scale (Jennings Scale, Phoenix, AZ). In order to cut down on hand shelling labor, two representative ears from each of the four variable rows (a total of eight representative ears) were collected for observation and additional measurements. These representative ears were visually identified as the ears that were the average size of all the ears within that variable row. In sample unit one only, at least three individual ears were harvested and individually weighed from the following plants: late emerged from third field visit, late emerged from fourth field visit, plants next to late emerged plants, plants with a normal emergence date, doubles, and skips. Ears next to a skip were harvested from plants on either side of the skip. Doubles were harvested by taking an ear from both plants situated in the double. These individual variable ears from sample unit one and the eight representative ears from sample unit one, two and three were placed in sealable plastic bags, labeled and transported 
to the office labs of the participating agents and specialists.

Eight representative ears from each sample unit were hand shelled. The grain collected from the eight representative ears was weighed using the UltraSport V2-30 scale scale (Jennings Scale, Phoenix, AZ). The empty cobs from the eight representative ears were weighed using the same scale. The grain weight was divided by the whole ear weight to calculate the shelling percentage. Moisture and test weight were measured on the grain and recorded using a mini GAC plus Grain Analysis Computer (DICKEY-John, Auburn, IL). The grain yield was adjusted to $15.5 \%$ moisture. The overall grain yield for each of the variable rows from sample unit one, two and three was calculated by applying the shelling percentage, adjusted grain moisture and area harvested.

Data were analyzed using appropriate models in PROC GLM with SAS 9.3 for Windows (SAS Institute, Cary, NC). Environment was considered as a random effect while treatment row was considered a fixed effect. A protected LSD ( $\mathrm{p} \leq$ 0.05 ) was used to compare means. A stepwise regression model was used to relate stand establishment outcomes as the dependent variables to a set of qualitative and quantitative independent variables. The independent variables that were included were; seeding rate, percent residue, tractor speed, previous crop, tillage type, soil temperature and soil moisture at planting. The entry significance level and stay significance level for independent variables was set at $p=0.15$. Each variable and model were given an adjusted $\mathrm{R}^{2}$ value along with an Akaike's Information Criteria (AIC) value. The adjusted $\mathrm{R}^{2}$ value represents the percentage of the variability the dependent variable that is explained by the variation of the independent variable. The variable or model with the largest adjusted $\mathrm{R}^{2}$ value was considered to have the best fit. The AIC value measures the model lack of fit and applies a penalty term as the number of independent variables in the model increases. The variable or model with the smallest AIC value is considered the best fit [12].

Relationships between stand establishment variability factors and field environment factors as well as planting methods were identified using a linear correlation model with significance level of $\mathrm{p} \leq 0.05$. The independent quantitative variables that were included were: percent residue, planting speed, soil temperature and seeding rate. The significance of regression coefficient slopes were tested using the t-test method.

\section{Results and Discussion}

\subsection{General Planting Conditions}

The median planting dates for fields observed in this research were generally about the middle of May for both years (Table 2), which was slightly earlier than the date when $50 \%$ of all the corn was planted for the state as a whole. However, the planting dates were still behind the states 5 -year average by approximately $40 \%$ in both years [13]. 
Table 2. Average air temperature, rainfall and planting date, accumulated growing degree days (AGDD) and average soil temperature for each ND region (NDAWN).

\begin{tabular}{ccccccc}
\hline Region & Year & $\begin{array}{c}\text { Avg. air temp. } \\
\left({ }^{\circ} \mathrm{C}\right)\end{array}$ & $\begin{array}{c}\text { Total rainfall } \\
(\mathrm{cm})\end{array}$ & $\begin{array}{c}\text { Planting } \\
\text { date }\end{array}$ & $\begin{array}{c}\text { Days to } 120 \\
\text { AGDD } \\
(\mathrm{d})\end{array}$ & $\begin{array}{c}\text { Avg. bare soil } \\
\text { temp. }^{\sharp} \\
\left({ }^{\circ} \mathrm{C}\right)\end{array}$ \\
\hline NE & 2013 & 11.6 & 15 & $5 / 18$ & 31 & 13.5 \\
& 2014 & 12.3 & 6 & $5 / 16$ & 14 & 15.9 \\
$\mathrm{NW}$ & 2013 & 11.8 & 14 & $5 / 17$ & 26 & 13.9 \\
& 2014 & 12.0 & 6 & $5 / 17$ & 16 & 16.8 \\
SE & 2013 & 13.0 & 11 & $5 / 12$ & 16 & 14.8 \\
& 2014 & 13.1 & 5 & $5 / 21$ & 12 & 19.7 \\
SW & 2013 & 12.3 & 20 & $5 / 7$ & 22 & 16.0 \\
\hline
\end{tabular}

${ }^{\dagger}$ Average air temperature for 1 May-31 May recorded by automated weather stations located within the region listed. ${ }^{\text {TT}}$ Total rainfall for $1 \mathrm{May}-31 \mathrm{May}$ recorded by automated weather stations located within the region listed. ${ }^{\S}$ Median planting date recorded by participating extension personnel for the locations within the region listed. 'Average number of days to 120 AGDD from planting date listed for that region. "Bare soil temperature is the temperature of bare soil with no vegetation at $10 \mathrm{~cm}$ below the soil surface, averaged over the two weeks after planting date listed for that region.

Rainfall during the month of May 2013 was substantially greater than the $7 \mathrm{~cm}$ average with an average departure from normal of $7 \mathrm{~cm}$, while rainfall conditions during the month of May 2014 was more comparable with only $-0.9 \mathrm{~cm}$ departure from normal [14]. In both years, rainfall averages were near normal throughout North Dakota for the remainder of the growing season. For 2013 and 2014, regional field locations had average air temperatures and bare soil temperatures close to the states 5 -year average of $12.5^{\circ} \mathrm{C}$ (Table 2).

The number of accumulated corn growing degree days (AGDD) needed from time of planting to time of emergence is about 120 [11]. The average amount of time to reach emergence in most seasons is approximately $14 \mathrm{~d}$, although in cool-soil conditions emergence can take up to $21 \mathrm{~d}$ [11]. The overall average number of days from planting to 120 AGDD in 2013 was $24 \mathrm{~d}$ while in 2014 the average number of days to emergence was closer to the expected time with $14 \mathrm{~d}$ (Table 2).

\subsection{Planting Methods and Field Environment}

Extension personnel recorded planter type, row spacing, seeding rate and planting speed for each field that was included in this study. Of the 38 fields observed, 31 were planted with a center fill hopper system seeder (Table 3 ). Fifty-six centimeter row spacing, planting rates of 76,000 to 89,000 seeds $/ \mathrm{ha}^{-1}$ and planting speeds of 7.3 to $8.0 \mathrm{~km} \mathrm{~h}^{-1}$ were the most frequently recorded planting techniques.

The fields were then evaluated for soil moisture at planting, percent residue, tillage type and previous crop (Table 4). The most frequent previous crop was soybean with 21 fields. Conventional tillage, percent residue of $21 \%$ to $30 \%$, and 
Table 3. Overview of corn planters, planting criteria and field environment for fields evaluated 2013 and 2014.

\begin{tabular}{cc}
\hline Factor/Measurement & No. fields \\
\hline Planter type & 31 \\
Center fill hopper & 7 \\
Individual hoppers & \\
Row spacing $(\mathrm{cm})$ & 9 \\
56 & 29 \\
76 & \\
Seeding rate $\left(\right.$ seeds ha $\left.{ }^{-1}\right)$ & 4 \\
$49,500-62,000$ & 12 \\
$63,000-75,000$ & 22 \\
$76,000-89,000$ & \\
Planting speed $\left(\mathrm{km} \mathrm{h}^{-1}\right)$ & \\
$6.4-7.2$ & 4 \\
$7.3-8.0$ & 18 \\
$8.9-12.0$ & 4 \\
\hline
\end{tabular}

${ }^{\dagger}$ Data were not available for five fields.

moist soil moisture at planting were the most frequently recorded field environments.

\subsection{Soil Compaction}

The presence of side wall soil compaction was investigated by digging away soil at the base of plants in at least one spot within the row. When reviewing data from all rows of all fields and sample units in the experiment, side wall compaction only occurred in five fields, primarily in 2013 when fields were planted in soggy conditions. Nevertheless, when reviewing data from rows that had been identified as being relatively more variable, side wall compaction was present in only two of these rows.

The Stutsman and Sargent County fields were measured for presence of soil compaction with the soil penetrometer resistance. The soil penetrometer resistance is said to mimic the resistance that would be encountered by a root. At 689 $\mathrm{kPa}$, approximately $69 \%$ of potential root penetration is expected and is considered to have little to no compaction [15].

The soil penetrometer readings from the rows with most variability had an average penetration resistance of $696 \mathrm{kPa}$ while the least variable rows had an average penetration resistance of $689 \mathrm{kPa}$. Therefore, it would seem soil compaction within the range encountered in these locations did not play a major role on the evenness of emergence or within-row plant spacing variability.

In 2014, any row planted within a tire track was documented in an attempt to 
Table 4. Overview of field environment evaluated 2013 and 2014.

\begin{tabular}{|c|c|}
\hline Factor/Measurement & No. fields \\
\hline \multicolumn{2}{|l|}{ Previous crop } \\
\hline Hordeum vulgare L. (Barley) & 4 \\
\hline Brassica napus L. (Canola) & 1 \\
\hline Zea mays L. (Corn) & 1 \\
\hline Phaseolus vulgaris L. (Dry bean) & 2 \\
\hline Triticum aestivum L. (Hard red spring wheat) & 7 \\
\hline Triticum aestivum L. (Hard red winter wheat) & 1 \\
\hline Pisum sativum L. (Pea) & 1 \\
\hline Glycine max L. (Soybean) & 21 \\
\hline \multicolumn{2}{|l|}{ Tillage type } \\
\hline Conventional & 21 \\
\hline Minimum & 2 \\
\hline No-Till & 8 \\
\hline Vertical & 5 \\
\hline \multicolumn{2}{|l|}{ Residue (\%) } \\
\hline $0-10$ & 3 \\
\hline $11-20$ & 8 \\
\hline $21-30$ & 12 \\
\hline $31-40$ & 6 \\
\hline $41-50$ & 1 \\
\hline $51-60$ & 2 \\
\hline $61-70$ & 3 \\
\hline $71->80$ & 3 \\
\hline \multicolumn{2}{|l|}{ Soil moisture ${ }^{\dagger}$} \\
\hline Dry & 1 \\
\hline Moist & 31 \\
\hline Soggy & 6 \\
\hline
\end{tabular}

${ }^{\dagger}$ Dry-soil that did not hold together when trying to form into a ball; Moist-soil that held together when made into a ball; Soggy — water from soil ran out of the formed ball and over the hand.

identify any increased stand establishment variability associated with planting implements and implement arrangements used by producers. Of the rows identified as having the greatest variability in emergence timing or within-row plant spacing variability, most came from rows not associated with any wheel track, regardless of type. If a wheel track was involved in a variable row, tracks made by the tractor or the planter were the most common. Wheel tracks made by a center-fill seed hopper, fertilizer hopper, or a combination of two or more wheel track types were the least commonly reported to have effect on emergence (data 
not shown).

\subsection{Stand Establishment Variability}

Stand establishment variability was defined as the occurrence of uneven plant emergence timing and within-row plant spacing variability. Equation (1) was used to determine which rows within a sample unit/field were most, second most, second least, and least variable in stand establishment variability.

It was expected that the least variable row would have the highest plant density with the least amount of change relative to the target population, most uniform with regards to timing of emergence, least number of uneven plant emergence timing and least occurrences of within-row plant spacing variability. The most variable row on the other hand would have the lowest plant density with the greatest amount of change relative to the target plant density, most uneven plant emergence timing and greatest within-row plant spacing variability. These expected outcomes did occur when reviewing general plant density characteristics of each variable row type (Table 5). However, in 2013, the second least and second most variable rows had the highest plant density. This unexpected outcome was attributed to the way variability was calculated in 2013, as it did not take into account the number of skips and doubles, or the total number of plants within the row. The least variable rows had the lowest average percent change $(-2)$ in target plant density compared with all other variable rows. The least variable row also had the lowest average plant-to-plant spacing $(19.5 \mathrm{~cm})$ and average standard deviation $(7 \mathrm{~cm})$.

Across all fields and sample units the average number of plants in a $9.14 \mathrm{~m}$ row was 44 . The most variable rows averaged across years had 19 occurrences of either within plant spacing variability or late emerged plants (Table 5) while the least variable row had an average of 10 occurrences.

Table 5. Average number of within-row plant spacing variability occurrences, late emerged plants, and plant density outcomes for each variable row type.

\begin{tabular}{|c|c|c|c|c|c|c|c|c|c|c|}
\hline \multirow{2}{*}{ Variability $^{\dagger}$} & Year & Skip ${ }^{\ddagger}$ & Double $^{\S}$ & LEearly & LElate ${ }^{\#}$ & Total occurrences & \multirow{2}{*}{$\begin{array}{l}\text { Avg. plant density } \\
\text { plants } \mathrm{ha}^{-1}\end{array}$} & \multirow{2}{*}{$\begin{array}{c}\text { Change from } \\
\text { planned } \\
\%\end{array}$} & \multirow{2}{*}{$\begin{array}{l}\text { Plant } \\
\text { spacing } \\
\mathrm{cm}\end{array}$} & \multirow{2}{*}{$\begin{array}{c}\text { Plant space SD } \\
\mathrm{cm}\end{array}$} \\
\hline & & & & no. & & & & & & \\
\hline \multirow[t]{2}{*}{ Most } & 2013 & 2 & 1 & 13 & 4 & 20 & 71,182 & -8 & 20 & 8 \\
\hline & 2014 & 5 & 1 & 9 & 2 & 17 & 70,605 & -7 & 21 & 9 \\
\hline \multirow[t]{2}{*}{ Second most } & 2013 & 2 & 1 & 14 & 3 & 20 & 72,757 & -7 & $\mathrm{NM}^{\dagger \dagger}$ & NM \\
\hline & 2014 & 5 & 1 & 9 & 1 & 16 & 72,579 & -5 & NM & NM \\
\hline \multirow[t]{2}{*}{ Second least } & 2013 & 1 & 1 & 9 & 1 & 12 & 74,936 & -5 & NM & NM \\
\hline & 2014 & 2 & 1 & 5 & 1 & 9 & 76,670 & -1 & NM & NM \\
\hline \multirow[t]{2}{*}{ Least } & 2013 & 1 & 1 & 9 & 1 & 12 & 72,207 & -5 & 19 & 7 \\
\hline & 2014 & 2 & 1 & 4 & 1 & 8 & 77,938 & +1 & 20 & 7 \\
\hline
\end{tabular}

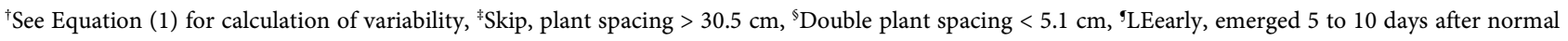
emerged plant, ${ }^{*}$ LElate, emerged 11 to 17 days after normal emerged plant, ${ }^{\dagger \dagger}$ Not measured. 
Second most variable and second least variable rows resulted in an average of 18 and 11 total variability occurrences, respectively. The type of stand establishment variability outcome that occurred most often per row were plants that emerged 5 to $10 \mathrm{~d}$ after NED plants (LEearly) with 4 to 14 plants row $^{-1}$, followed by skips ( 1 to 5 plants/row ${ }^{-1}$ ). Doubles occurred the least often with an average of 1 plant $/$ row $^{-1}$.

In 2013, uneven plant emergence timing had more occurrences than within-row plant spacing variability. In 2014, within-row plant spacing variability had more occurrences than uneven plant emergence timing. The explanation for the differences between the two years could be attributed to soil moisture and rainfall. Rainfall during the planting season was considerably higher in 2013 than in 2014 (Table 2). It was also the only year for which soggy soil planting conditions were recorded. The presence of high soil moisture may have caused inadequate seed to soil contact due to side wall compaction, therefore inhibiting seed emergence [6]. Reduced rainfall during the planting season in 2014 may have encouraged increased planting speeds. Producers often view dry weather conditions as an optimum planting window and set goals to complete as much planting as possible. Lauer and Rankin [10], found an increase in within-row plant spacing standard deviation when planting speeds increased from 6 to 13 $\mathrm{km} \mathrm{h}^{-1}$.

\subsection{Impact of Uneven Emergence Timing and Within-Row Plant Spacing Variability on Individual Plant Yields}

Ears from plants with delayed emergence dates, or sub-optimal within-row plant to plant spacing were harvested and weighted to quantify the effects of emergence timing and spacing on individual plant yield. It is understood that late-emerged plants must compete with larger neighboring plants for resources, often resulting in smaller ears [3]. Past studies have shown that individual plants situated next to a skip or double have a difference in individual ear weight, but when the occurrence is frequent the impact on overall plot yield is minimal ( $1 \%$ to $2 \%)$ [2] [5].

Data from all locations and both years shows uneven plant emergence timing and within-row plant spacing variability does affect individual ear weight ( $\mathrm{p} \leq$ 0.0001). However, the effect on individual ear weight changed depending on the type of emergence timing or within-row plant spacing variability (Table 6).

Individual ears from plants with delayed emergence, LEearly and LElate (11 to $17 \mathrm{~d}$ delay), had significantly less yield when compared with the plants that emerged at the normal dates (NED) (Table 6). Plants that were considered LEearly were approximately two leaves behind normal plants (data not shown). These ears weighed 35\% less, than the average weight of NED ears. Ears from LElate plants, which were approximately 4 leaves behind the normal emerged plants, weighed $41 \%$ less than the average weight of NED ears. These results are consistent with the yield decline Liu et al. [2] found with 2-leaf and 4-leaf emergence 
Table 6. Weight of an individual ear as affected by plant spatial arrangement and emergence timing expressed as a percent of the mean weight of the ear from a normal emerged plant over both years.

\begin{tabular}{cc}
\hline Individual ear $^{\dagger}$ & Relative weight, \% \\
\hline Next to skip & 111 \\
Next to late emerged plant & 105 \\
Normal emergence date & 100 \\
Double 1 & 86 \\
LEearly & 65 \\
LElate & 59 \\
Double 2 & 50 \\
LSD $(p \leq 0.05)$ & 15 \\
\hline
\end{tabular}

${ }^{\dagger}$ Skip, $>30.5 \mathrm{~cm}$; Double $1,<5.1 \mathrm{~cm}$, ear from largest plant; LEearly, emerged 5 - 10 days after normal emergence date; LElate, emerged 11 - 17 days after normal emergence date; Double 2, $<5.1 \mathrm{~cm}$, ear from smallest plant.

delay. Both values are significantly different than the weight of the NED ( $\mathrm{p} \leq$ 0.05). Weight reductions of the late-emerging plants were only moderately offset by neighboring plants that emerged normally. Plants next to late-emerged plants (NLE) had ears that weighed 5\% greater than plants with a NED. This was a non-significant difference in weight when compared with NED. Ears from plants situated next to a $30.5 \mathrm{~cm}$ skip had an average weight of $11 \%$ more than the NED ears. However, this increase was not enough to compensate for the missing plant and is not significantly different than the NED ears. The two plants situated as doubles, individually weighed substantially less than the NED, but together, the ears weighed an average of $36 \%$ more than the NED. This increase does contribute to an increase in yield. The results for percent weight of within-row spacing variable ears is similar to the findings reported by others [2] [5].

\subsection{Impact of Uneven Emergence Timing and Within-Row Plant Spacing Variability on Overall Yield within a Given Location}

As previously described, it was found that uneven emergence and within-row plant-to-plant spacing variability did impact individual plant yield. The next step in the process was to quantify the impact of uneven emergence timing and within-row plant spacing variability on overall yield.

This was achieved by measuring yield from the most, second most, second least, and least variable rows from each sample unit. It was expected that the most variable row would yield the least when compared with the other variable rows, while the least variable row would have the greatest yield.

In 2013, averaged across all field locations, the most variable row yielded 9651 $\mathrm{kg} \mathrm{ha}^{-1}$ and the least variable row yielded 10,002 $\mathrm{kg} \mathrm{ha}^{-1}$ (Table 5). When data were analyzed using a combined analysis for all locations in 2013, yield was not impacted by uneven plant emergence timing and within-row plant spacing va- 
riability $(\mathrm{P}=0.67)$ (Table 7$)$. However, this result could be due to how variability was selected in 2013. For that year, variability was identified only by calculating the change in plant density over time and did not include total number of plants, skips, or doubles within the row. This issue was recognized and the method of variable row identification was modified in 2014 and Equation (1) was implemented. When all data were collected in 2014, yield was significantly impacted by uneven plant emergence timing and within-row plant spacing variability ( $\mathrm{p} \leq 0.0001)$. The most variable row yielded $9 \%$ less $\left(9666 \mathrm{~kg} \mathrm{ha}^{-1}\right)$ than the least variable row $\left(10,592 \mathrm{~kg} \mathrm{ha}^{-1}\right)$ (Table 7$)$.

When combining both years and all locations, uneven plant emergence timing and within-row plant spacing variability had a significant impact on yield ( $\mathrm{p} \leq$ $0.0021)$. The most variable row yielded $6 \%\left(9658 \mathrm{~kg} \mathrm{ha}^{-1}\right)$ less than the least variable row $\left(10,278 \mathrm{~kg} \mathrm{ha}^{-1}\right)$. The yield decline for the variable rows in all cases can be attributed the increased occurrences of late emerging plants (LEearly and LElate) and skips, which are known to impact the weight of individual ears and overall yield (Table 6). When these individual types of stand establishment outcomes are assessed on a group basis (Table 7) and quantified for differences in yield (Table 7), stand establishment variability within the width of a planter causes a decrease in overall yield.

Nafzinger et al. (1991) states the effect on yield is heavily dependent on the proportion of the overall stand that is delayed. This statement could be taken further too also include within-row plant spacing variability.

For example, when assessing stand establishment outcomes individually, if the total percentage of plant density (based on 74,100 plants ha ${ }^{-1}$ ) has $10 \%, 20 \%$ and $30 \%$ occurrences of skips, there is an estimated yield loss of $8 \%, 17 \%$, and $25 \%$ respectively (Table 8 ). The percentage yield loss results (2\% to $6 \%$ ) for LElate (Table 8) were similar to Nafzinger et al. [4] findings of a $6 \%$ yield decline when $25 \%$ of the plant stand had a 10 to $12 \mathrm{~d}$ delay in emergence. Liu et al. [2] reported $4 \%$ and $8 \%$ yield decline when $17 \%$ of the plant stand had a delay in emergence of $12 \mathrm{~d}$ and $21 \mathrm{~d}$ respectively. However, it is rare to experience only one type of stand establishment outcome in the field, and producers should

Table 7. Effect of emergence and within row plant space variability on grain yield.

\begin{tabular}{cccc}
\hline & \multicolumn{3}{c}{ Grain Yield } \\
\cline { 2 - 3 } Variability $^{\dagger}$ & 2013 & 2014 & Mean \\
\cline { 2 - 4 } Most & 9651 & $\mathrm{~kg} \mathrm{ha}^{-1}$ & 9658 \\
Second most & 9810 & 9666 & 9773 \\
Second least & 9887 & 10444 & 10148 \\
Least & 10002 & 10592 & 10278 \\
LSD $(p \leq 0.05)$ & 552 & 340 & 341 \\
\hline
\end{tabular}

${ }^{\dagger}$ See Equation (1) for definition of variability. 
Table 8. Estimated percent overall yield loss or gain for each stand establishment outcome with occurrences of $10 \%, 20 \%$, and $30 \%$ of the total plant density.

\begin{tabular}{ccccc}
\hline & \multicolumn{4}{c}{ Stand establishment outcome } \\
\cline { 2 - 4 } Total plant density $\%$ & Skip & LEearly & LElate & Double \\
\cline { 2 - 4 } & \multicolumn{4}{c}{ yield loss/gain, \% } \\
\hline 10 & -8 & -1 & -2 & 3 \\
20 & -17 & -2 & -5 & 7 \\
30 & -25 & -2 & -6 & 10 \\
\hline
\end{tabular}

${ }^{\dagger}$ Skip, plant spacing $>30.5 \mathrm{~cm}$; Double, $<5.1 \mathrm{~cm}$; LEearly, emerged 5 - $10 \mathrm{~d}$ after normal emerged plant; LElate, emerged $11-17 \mathrm{~d}$ after normal emerged plant. ${ }^{\ddagger}$ Based on 74,100 plants ha ${ }^{-1}$.

expect a combination of outcome types. In this experiment, overall yield declined by an average of $4 \%$ when an average of 36\% (approximately 1 in 3 plants) of the plant density had a combination of all four types of stand establishment variability outcomes occurring.

\subsection{Factors Impacting Stand Establishment Variability}

Since this study has confirmed that stand establishment variability does impact individual ear and overall yield of corn, the next step in the process was to identify factors that might cause greater stand establishment variability and to quantify how they might impact stand establishment variability. However, this proved to be difficult, as very few field environments had the same types or amounts of unfavorable planting conditions at the same time. Linear prediction models were used to estimate the impact of measured factors on plant stand variability in order to aid producers in understanding what field environments and planting methods impact uneven plant emergence timing and within-row plant spacing variability.

Stepwise regression was used to develop the best linear prediction model for overall variability, skips, doubles, LEearly and LElate stand establishment outcomes. Both quantitative and qualitative field environment and planting method variables were included in the model. The following variables were included: previous crop (PC), soil moisture at planting (SM), tillage type (T), percent residue (PR), speed of planter (S), speed by speed (SxS), seeding rate (SR) and soil temperature (ST).

Based on stepwise regression the following variables were found to significantly impact overall variability (V) shown in the following equations for 2013 (Equation (2)), and combined years (Equation (3)):

$$
\begin{gathered}
\mathrm{V}=\mathrm{b} 0+\mathrm{b} 1 \mathrm{SR}+\mathrm{b} 2 \mathrm{~T}+\mathrm{b} 3 \mathrm{ST}\left(\mathrm{adj} . \mathrm{R}^{2}=0.46 ; \mathrm{AIC}=-22\right) \\
\mathrm{V}=\mathrm{b} 0+\mathrm{b} 1 \mathrm{PCxT}+\mathrm{b} 2 \mathrm{SxS}+\mathrm{b} 3 \mathrm{~S}\left(\text { adj. } \mathrm{R}^{2}=0.80 ; \mathrm{AIC}=-81\right)
\end{gathered}
$$

The adjusted $\mathrm{R}^{2}$ values for Equation (2) and Equation (3) were quite high, while the AIC values were very low, indicating that the models were effective in identifying variables implicated in increasing variability. However, the adjusted 
$\mathrm{R}^{2}$ values for 2014 was indicative that most of the variability was not explained by the independent variables (ST) included in the model.

Based on stepwise regression the following variables were found to significantly impact the number of skips (Sk) shown in the following equations for 2013 (Equation (4)), 2014 (Equation (5)).

$$
\begin{gathered}
\mathrm{Sk}=\mathrm{b} 0+\mathrm{b} 1 \mathrm{~T}+\mathrm{b} 2 \mathrm{PR}\left(\operatorname{adj} . \mathrm{R}^{2}=0.45 ; \mathrm{AIC}=7\right) \\
\mathrm{Sk}=\mathrm{b} 0+\mathrm{b} 1 \mathrm{Sx} \mathrm{S}+\mathrm{b} 2 \mathrm{~S}+\mathrm{b} 3 \mathrm{~T}+\mathrm{b} 4 \mathrm{PR}\left(\operatorname{adj} . \mathrm{R}^{2}=0.85 ; \mathrm{AIC}=9\right)
\end{gathered}
$$

The adjusted $\mathrm{R}^{2}$ values for Equation (5) and Equation (6) were quite high, and the AIC values were low, indicating that the models were effective in identifying variables implicated in increasing variability. However, the adjusted $\mathrm{R}^{2}$ values for combined years was indicative that most was not explained by those independent variables.

Based on stepwise regression the following variables were found to significantly impact LEearly (LE) shown in the following equations for 2013 (Equation (6)), 2014 (Equation (7)) and combined years (Equation (8)):

$$
\begin{aligned}
\mathrm{LE}= & \mathrm{b} 0+\mathrm{b} 1 \mathrm{PR}+\mathrm{b} 2 \mathrm{~S}+\mathrm{b} 3 \mathrm{SxS}\left(\mathrm{adj} . \mathrm{R}^{2}=0.69 ; \mathrm{AIC}=66\right) \\
& \mathrm{LE}=\mathrm{b} 0+\mathrm{b} 1 \mathrm{PR}+\mathrm{b} 2 \mathrm{PC}\left(\mathrm{adj} \cdot \mathrm{R}^{2}=0.41 ; \mathrm{AIC}=43\right) \\
\mathrm{LE}= & \mathrm{b} 0+\mathrm{b} 1 \mathrm{PR}+\mathrm{b} 2 \mathrm{PCxT}+\mathrm{b} 3 \mathrm{SxS}+\mathrm{b} 4 \mathrm{ST} x \mathrm{ST}+\mathrm{b} 5 \mathrm{SR} x \mathrm{PC} \\
& +\mathrm{b} 6 \mathrm{SR} x \mathrm{SR}+\mathrm{b} 7 \mathrm{ST}\left(\operatorname{adj} \cdot \mathrm{R}^{2}=0.94 ; \mathrm{AIC}=62\right)
\end{aligned}
$$

Based on stepwise regression of number of doubles and LElate (LL) with field environment and planting method variables, no equations were predictive.

Although it was difficult to identify a specific prediction model to calculate expected stand establishment variability, certain field environments and planting method variables have a consistent presence in the models. These independent variables represent a significant contributing factor to overall stand establishment variability, uneven emergence timing, and within plant spacing variability outcomes. The independent variables with the most occurrences were percent residue and tractor speed, followed by previous crop, tillage, and soil temperature.

The majority of the fields in this experiment were planted in fields with residue cover ranging from $21 \%$ to $40 \%$ (Table 4 ). The amount of residue cover has the ability to cause other undesirable planting conditions that are known to impact stand establishment variability. Past studies have shown that percent residue induces uneven soil temperatures and soil moisture [6]. Planting issues that cause a lack of consistent planting depth, reduced ability of planter performance, and reduced seed to soil contact can also occur in high residue fields [16].

Studies have shown that increasing planting speed causes a decrease in yield and an increase in within-row plant spacing variability. Lauer and Rankin [10] found a decrease in yield of $4 \%$ when speed increased from 6.4 to $12.8 \mathrm{~km} \mathrm{~h}^{-1}$, as well as an increase in plant spacing standard deviation when speeds increased 
from 6.4 to $12.8 \mathrm{~km} \mathrm{~h}^{-1}$. A study conducted by Liu et al. [9] also found an increase of plant spacing standard deviation as planting speed increased. In their research, the greatest effect from speed was under no-till when speeds increased from 7.2 to $11.3 \mathrm{~km} \mathrm{~h}^{-1}$. In the fields monitored in the research reported here, the majority of planting speeds ranged from 7.3 to $8.8 \mathrm{~km} \mathrm{~h}^{-1}$ (Table 3 ).

The model for overall variability in combined years (Equation (7)) includes an interaction of previous crop with tillage. In this study, there were too few observations of certain previous crop type in order to make a statistical inference on which previous crop has the greatest impact on uneven plant emergence and within-row plant spacing (Table 4). A study conducted by Duvick et al. [17] found that a corn-corn rotation with no-till had the greatest negative effect on yield and growth when compared with corn-soybean with conventional till.

Soil temperatures at planting are typically below the optimum $29^{\circ} \mathrm{C}$ for corn germination and emergence [16]. In this experiment, the bare soil temperature averaged over two weeks after the planting date for all locations over both years was $15.8^{\circ} \mathrm{C}$. Varying soil temperatures can be attributed to physical characteristics of the soil such as color and texture [6]. However, the amount of residue on the soil surface also plays an important role in soil temperature. Heavy residue areas will be cooler than others, also whole fields can experience reduced soil temperatures in reduced tillage systems [1] [6].

Most research studying the impact of uneven emergence and within-row plant space variability on yield has been conducted on small scale, hand planted plots. Some research has been done to identify factors that impact stand establishment variability. These studies were conducted on fields planted with farming implements in large scale fields. However, even these experiments applied the field environments or planting methods in question as controlled factors to the field, or identified one as the main contributing limiting factor in that field. This type of design aided the researchers to more accurately identify the level of impact the specific field environment or planting method had on stand establishment variability. Future experiments could be conducted locally in order to generate accurate prediction models for stand establishment variability in North Dakota.

\section{Conclusions}

Uneven plant emergence timing and within-row plant spacing variability effects on corn yield generally followed the expected trends based on the results of previous research. Despite the differences in rainfall and rate of AGDD between the two years, corn yield responded similarly to uneven plant emergence timing and within-row plant space variability in both years. Uneven plant emergence timing impacted individual ear weight. The amount of per plant yield loss due to uneven emergence increases ( $35 \%$ to $41 \%$ ) as the number of days ( 5 to $17 \mathrm{~d}$ ) after normal emergence date. Plants that emerged 11 to $17 \mathrm{~d}$ after the normal emergence date had the greatest impact on individual ear yield loss (41\%). The type of uneven plant emergence timing that occurred most frequently was 5 to $10 \mathrm{~d}$ 
after normal emergence date. Within-row plant spacing variability impacted individual ear weight. The amount of loss due to within-row plant spacing variability is dependent on the type: skip or double. Plants next to skips had a greater weight by $11 \%$ compared with the normal emergence date ear, but did not compensate for the missing ear. When two plants situated in the double are combined, there is a $35 \%$ increase in ear weight. The type of within-row plant spacing variability that occurred most frequently was skips, plants greater than $30.5 \mathrm{~cm}$ apart.

Uneven plant emergence timing and within-row plant spacing variability cause overall yield loss. When averaging yield from both years and all locations for each variable row type, the most variable row yielded significantly less (9658 $\left.\mathrm{kg} \mathrm{ha}^{-1}\right)$ than the least variable row $\left(10,278 \mathrm{~kg} \mathrm{ha}^{-1}\right)$. The percentage of overall yield loss is dependent on the proportion of the overall stand that is delayed [4]. In this study, when an average of 36\% (approximately 1 in 3 plants) of the plant density had a combination of stand establishment variability, overall yield declined by an average of $4 \%$.

The key factors contributing to uneven plant emergence timing and within-row plant spacing variability were percent residue, planting speed, previous crop, tillage and soil temperature. Past studies have identified specific field environments and planting methods such as soil temperature, soil moisture, tillage type, percent residue, soil compaction, planter type and planting speed to have an effect on uneven plant emergence timing and within-row plant space variability [1] [2] [7] [9] [10] [18] [19]. It is important that the producer has an understanding that these field environments and planting methods do have an impact on final stand establishment. It is also important the producer understands the presence of uneven emergence and skips will reduce yields. Producers must apply these indications and assess each field individually in order to make best management decisions that will lead to reduced uneven plant emergence timing and within-row plant spacing variability.

\section{Acknowledgements}

Novak thanks the North Dakota State University Extension Agents and Specialist for their help in collecting data. Specifically, Roger Ashley, Tim Becker, Melissa Blawat, Greg Endres, Dr. Shana Forester, Randy Grueneich, Alicia Harstad, Bill Hodus, Scott Knoke, Joel Lemer, Lindsay Maddock, Kim Nelson, Al Ulmer and LoAyne Voigt. The financial support of the North Dakota Corn Council is gratefully acknowledged.

\section{Conflicts of Interest}

The authors declare no conflicts of interest regarding the publication of this paper.

\section{References}

[1] Carter, P.R., Nafziger, E.D. and Lauer, J.G. (2001) Uneven Emergence in Corn. 
North Central Regional Extension Publication No. 344.

[2] Liu, W., Tollenaar, M., Stewart, G. and Deen, W. (2004) Response of Corn Grain Yield to Spatial and Temporal Variability in Emergence. Crop Science, 44, 847-854. https://doi.org/10.2135/cropsci2004.8470

[3] Maddonni, G.A. and Otegui, M.E. (2004) Intra-Specific Competition in Maize: Early Establishment of Hierarchies among Plants Affects Final Kernel Set. Field Crops Research, 85, 1-13. https://doi.org/10.1016/S0378-4290(03)00104-7

[4] Nafzinger, E.D., Carter, P.R. and Graham, E.E. (1991) Response of Corn to Uneven Emergence. Crop Science, 31, 811-815. https://doi.org/10.2135/cropsci1991.0011183X003100030053x

[5] Doerge, T.D., Jeschke, M. and Carter, P. (2015) Planting Outcome Effects on Corn Yield. Dupont Pioneer Agronomy Services, Crop Insight, 25:1.

[6] Nielsen, D.L. (2001) Stand Establishment Variability in Corn. Department of Agronomy Publication AGRY-91-01, Purdue University, West Lafayette, IN.

[7] Saab, I. (2012) Stress Emergence in Corn. Pioneer Crop Insights 22:8.

[8] Nielsen, D.L. (2015) Requirements for Uniform Germination of Emergence of Corn. Purdue University Department of Agronomy Corny News Network. http://kingcorn.org/news/articles_15/

[9] Liu, W., Tollenaar, M., Stewart, G. and Deen, W. (2004) Impact of Planter Type, Planting Speed, and Tillage on Stand Uniformity and Yield of Corn. Agronomy Journal, 96, 1668-1672. https://doi.org/10.2134/agronj2004.1668

[10] Lauer, J.G. and Rankin, M. (2004) Corn Response to Within Row Plant Spacing Variation. Agronomy Journal, 96, 1464-1468.

https://doi.org/10.2134/agronj2004.1464

[11] Nielsen, D.L. (2014) The Emergence Process in Corn. Purdue University Department of Agronomy Corny News Network.

http://kingcorn.org/news/timeless/Emergence.html

[12] Beal, D.J. (2007) Information Criteria Methods in SAS for Multiple Linear Regression Models. SESUG 2007: The Proceedings of the South East SAS Users Group, Hilton Head, SC, 2007.

[13] NASS USDA National Agriculture Statistics Service, United States Department of Agriculture (2013) North Dakota Crop Progress and Condition Report. Washington DC.

http://www.nass.usda.gov/Statistics_by_State/North_Dakota/Publications/Crop_Pr ogress_\&_Condition/index.asp

[14] NDAWN North Dakota Agriculture Weather Network (2015) Monthly Data Table Form. http://ndawn.ndsu.nodak.edu/weather-data-monthly.html

[15] Duiker, S.W. (2002) Diagnosing Soil Compaction Using a Soil Penetrometer. Penn State Extension Agronomy Fact Sheet 63.

[16] Stoll, M. and Saab, I. (2010) Maximizing Corn Emergence and Uniformity in High Residue Fields. Dupont Pioneer Agronomy Services Crop Insights 20:10.

[17] Duvick, D.N. (1997) What Is Yield? In: Edmeades, G.O., et al., Eds., Developing Drought and Low N-Tolerant Corn, CIMMYT, El Batan, 332-335.

[18] Boomsma, C.R., Santini, J.B., West, T.D., Brewer, J.C., McIntyre, L.M. and Vyn, T.J. (2010) Maize Grain Yield Responses to Plant Height Variability Resulting From Crop rotation and Tillage System in a Long-Term Experiment. Soil and Tillage Re- 
search, 106, 227-240.

[19] Ramazan, M., Khan, G.D., Hanif, M. and Ali, S. (2012) Impact of Soil Compaction on Root Length and Yield of Corn (Zea mays) under Irrigated Condition. Middle-East Journal of Scientific Research, 11, 382-385. 